1936, 2135, Nr: 52. - Rein, Z. Kreislaufforschg 23, 365 (1931). - Richter, Virchows Arch. 299, 637 (1937). - E. Ro mberg, Münch. med. Wschr. 1932, Nr. 26 und 27. - R. Rössle, Wachstum und Altern (Berlin 1923); Münch. med. Wschr. 1910, Nr. 19, 993. - R. Rössle und F. Roulet, Maß und Zahl in der Pathologie (Berlin 1932). - H. L. Smith, Zbl. Path. 68, Nr. 1 (1937), Ref. - Spalteholz in Si g 1 bauer, Anatomie des Menschen (Berlin 1930). - Ste in berg, Zieglers Beitr. 82, 443 (1929). - Stephan, Z. Kreislaufforschg 26, 845 (1934). - Saltykow, Virchows Arch. 272, 442 (1929). - Schmidtmann, Virchows Arch. 255, 206 (1925). - E. Stiller, Die asthenische Konstitutionskrankheit (Stuttgart 1907). Thoma, Zieglers Beitr. 66, 92 (1920). - Thölld te, Zieglers Beitr. 77, 61 (1927). Troitzkaja und Andreewa, Frankf. Z. Path. 41, 120 (1931); Virchows Arch. 262, 81 (1926). - H. de Waart und C. J. Storm, Koumans (Batavia), Amer. Heart J. 12, 70 (1936), ref. Z. Kreislaufforschg 29, 257 (1937). — Whit ten, Z. Kreislaufforschg 22, 558 (1930). - K. Wolk off, Zieglers Beitr. 82, 555 (1929); Virchows Arch. 241, 42 (1923); 252, 208 (1924); 256, 751 (1925). - Zinserling, Virchows Arch. 255, 676 (1925); Zieglers Beitr. 94, 20 (1934/35).

\title{
Berichtigung zu Band II, Heft 9-12.
}

In der Arbeit Strubell-Harkort und Sorber, Ein neues Hitzdrahtanemometer für die Zwecke der Pneumotachographie, im Archiv für Kreislaufforschung, Bd. Il, Heft 9-12, Seite 376 (1938), muß die Formel auf Seite 377 Mitte richtig heiBen:

$$
\frac{\underline{\varrho}_{100}-\varrho_{0}}{\varrho_{0}}=0,4
$$

